\title{
An Exploratory Analysis of the Relationships between Personality Characteristics and the Perceptions of Virtual Merchandising
}

\author{
Al Bellamy, Julie Becker \\ School of Technology Studies, Eastern Michigan University, Ypsilanti, USA \\ Email: Al.bellamy@emich.edu, Jbecker2@emich.edu \\ Received 7 February 2015; accepted 12 March 2015; published 16 March 2015 \\ Copyright (C) 2015 by authors and Scientific Research Publishing Inc. \\ This work is licensed under the Creative Commons Attribution International License (CC BY). \\ http://creativecommons.org/licenses/by/4.0/

(c) (i) Open Access

\begin{abstract}
This study explored the relationship between individual's perception of presence within a virtual merchandising environment and their attitudes toward virtual shopping. Symbolic interactionism was used as the theoretical framework. Utilizing four of the Big Five personality framework, it also examined if individual's personality affected their attitude toward virtual shopping as well as the relationship between presence and attitudes toward online shopping. The study was conducted among 81 students enrolled in an undergraduate Apparel Textiles and Merchandising Program at a university located in Southeastern Michigan. Results indicate a positive correlation between perceptions of presence and individual willingness to make purchases within an online shopping environment as well as their overall satisfaction with shopping in such an environment. Two of the personality factors from the Big Five personality framework, neuroticism and extroversion, were shown to moderate these relationships. Overall, the study confirmed the idea that individual personality traits affect one's disposition towards shopping within a virtual environment.
\end{abstract}

\section{Keywords}

Virtual Merchandising, Symbolic Interaction Theory, Personality Factors, Shopping Attitudes

\section{Introduction}

The emergence of the information epoch is weakening the hegemony of brick and mortar merchandising. Shopping within the traditional "store" provides a host of symbolic nuances to the consumer that helps to give definition and a sense of presence to the shopping experience. The virtual structure of online shopping annuls many of the symbols that shoppers are familiar with within traditional shopping including social interaction. Subse- 
quently, designers of online shopping platforms will need to be cognizant of the idea that shopping is not just an economic activity but rather is also a process that is linked to various social psychological factors that help to define a person's sense of being. This suggests that there is a dire need for empirically examining the interface between the structure of online shopping and various psychological orientations of the shopper. Companies such as The Gap, Forever21, Victoria Secret, Nike, Target, Abercrombie \& Fitch, and Macy’s are using Internet technology to merchandise the product to the consumer to make the sale. Merchants need to understand the basics of color trends, fabrics, and silhouette designs while gaining a better understanding of how psychological orientation affects consumer perception of online shopping. In doing so, they will improve their position to more effectively leverage their online shopping strategy. Very few empirical investigations have codified the relationship between various consumer personality orientations and the nature of their interface with online shopping.

This study examined the influence of consumers' sense of presence within a virtual environment on their attitudes towards online shopping within the context of symbolic interaction theory. It further examined the extent to which personality factors moderate this relationship. The moderator variable consisted of four factors within the Big Five personality inventory comprised of openness, conscientiousness, extraversion, and neuroticism of the consumer.

The paper will proceed as follows: it will first present an overview of symbolic interactionism as the theoretical framework of the study. It will then provide an overview of presence and the personality factors examined within the study. It will follow with a description of the methods utilized within the study followed by the results and discussion.

\subsection{Symbolic Interactionism as a Framework for Analyzing Online Shopping}

Symbolic interactionism is a major sociological framework that emphasizes the symbolic and subjective meaning that individuals attach to things, people and their environment. The manner in which people act towards people and their environment is based upon the meanings attached to the symbols within a given situation. This framework has been used within a large number and types of conceptual and empirical studies including several investigations pertaining to retail shopping (Langman, 1990; Pennartz, 1989). However, very few if any studies have been conducted utilizing this framework within the realm of virtual merchandising. The presentation of digital symbols within online shopping is closely aligned with the basic tenets of symbolic interactionism whose theoretical focus is on the ways in which symbols contribute to the means in which humans construct their realities of various types of situations. George Herbert Mead (1934) [1] put forth the basic tenets of the symbolic interactionist perspective consisting of:

1) Individuals confront their environment by perceiving and interpreting the symbols contained within that environment.

2) Individuals "define the nature of a situation", wherein they are "capable of orienting themselves to a vast constellation of social and physical objects. The brick and mortar store represents the conventional mode of shopping. It contains a vast amount of symbols, including face-to-face human interaction that yields cohesive meaning and understanding of the shopping experience that facilitates the shopper's process of defining the situation. The shopper is fully immersed within a three dimensional structure of the brick and mortar store. The online store, however, is a two dimensional structure. The reality of the symbols are therefore different prompting the need to investigate how these digital symbols are affecting the consumer's sense of presence within this type of environment. Furthermore, shopping online within a virtual environment does not contain human interaction (at least at this point in time) which is so vital to establishing meaning to any particular situation. On the other hand, the virtual store does indeed contain a large number of symbols in the form of merchandising, text, color, etc. However, the physical orientation of these things is substantially different than what is found within the brick and mortar store. The utilization of human senses such as touch and smell are missing-things essential for giving meaning and understanding of a specific situation. The absence of these things gives more salience to providing more systematic attention to how objects are presented and configured within the virtual space.

3) Through a process called “taking the role of the other”, people are able to anticipate each other's responses based upon the richness of the symbolic information existing within a given social situation. As stated above, face-to-face interaction is missing in a virtual shopping experience. However, as outlined by Mead, taking the role of the other is more of a learned cognitive process occurring within the mind than something that transpires 
within actual interaction episodes. Previous interaction episodes are internalized to form the mind. In fact, Mead asserts that taking the role of the other is the foundation of the human mind. As such, mind, within this context is presented as both a sociological entity as well as social psychological. Taking the role of the other which also includes objects as well as people, entails cognitively rehearsing (imaginative rehearsal) ones behavior and thoughts prior to reacting to people and objects. This is not only a psychological process, but a psychological process that has been learned through the interaction (sociological) with others over time. In short, our proposition within the context of symbolic interaction theory is that individuals traversing a virtual shopping environment is not entirely a psychological experience. Rather they take with them internalized social rules (the mind) for interacting with virtual objects as well as social experiences for defining those objects situations that are used to approximate the nature of virtual shopping situations (Bellamy \& Hanewicz, 1999, p. 1) [2].

The symbolic interaction framework interfaces well with the factors of presence and the personality dimensions chosen for investigation within the present study.

\subsubsection{Presence}

Several factors have been identified in the empirical literature that relate to consumers' perceptions toward virtual merchandising and their willingness to make purchases within a virtual store environment. These factors include customer personalization of the shopping process (Venkatesh \& Agarwal, 2006; Vogelstein, 2003) [3] [4], customer attitude toward the usability and usefulness of the online shopping experience (Childers, et al., 2002; Kim, et al., 2003) [5] [6], the examination of the effects of image interactivity technology (Lee, et al., 2010; Yang \& Wu, 2009) [7] [8] and consumer personality (Barkhi \& Wallace, 2007) [9]. An apparently important factor that has not been systematically investigated within the context of virtual merchandising is consumers' perceptions of the degree of presence of the virtual merchandising platform. Presence has been defined as "the subjective experience of being in one place or environment, even when one is physically situated in another" (Witmer \& Singer, 1998, p. 225) [10]. Several dimensions have been identified as affecting the degree to which a person experiences presence within a virtual environment that would be relevant to virtual merchandising: the amount of perceived social richness, the amount of perceptual realism of the virtual platform, and the extent to which the person has a sense of being immersed within the virtual space (Lombard \& Ditton, 1997) [11]. All of these factors are tied to the richness and structure of the symbols present within the virtual environment. According to symbolic interaction theory, these factors could provide the framework for an individual to interpret the meaning and subsequent action of the individual in the form of making a purchase or deciding not to consume. This study focused on each of these dimensions with the exception of social richness. The expectation was that increased perceived levels of presence within the virtual merchandising environment would correspond with increases in consumers' satisfaction of the virtual shopping experience along with their willingness to engage in virtual shopping.

The predominant characteristic of a virtual merchandising environment is the existence of symbols presented digitally. The term virtual pertains to the realness of a technological display of objects in which the consumer "defines" the objects as being real. The extent to which these displays are experienced as real is expected to influence his/her attitudes and behaviors toward this type of environment. What is missing from this type of shopping experience is the social equation. However, the social process as conceptualized within the symbolic interaction framework is an internalized mental phenomenon in which the individual engages in an "imaginative rehearsal” with others. Most virtual merchandising websites, as well as the website for this investigation, did not include actual social aspects; we contend that the social process does indeed occur within the mind of the consumer while shopping. We further propose that this process, along with the other dimensions postulated within the symbolic interaction framework occurs within the virtual merchandising environment. The fecundity in which they serve to influence consumer attitudes and behaviors will be affected by their perceptions of the degree of presence of the virtual shopping experience as well as the design of the online shopping website.

\subsubsection{Personality Factors}

The extent to which personality affects purchasing decisions in virtual stores has been examined within the empirical literature (Barkhi \& Wallace, 2007) [9]. This study has methodologically positioned consumer personality as a moderator factor influencing the relationships between perceived presence, consumer attitudes, and behaviors within online stores. It also examined the direct impact of personality types on the criterion variables. 
The personality orientation of a consumer is understood within the symbolic interaction framework as a variable that would affect how a person would define the virtual environment. We chose four of the dimensions from the Big Five personality theory (Goldberg, 1993) [12] within the present study that appeared to be congruent with the objectives of the research. Each of the chosen factors seems to be more aligned with how individuals may interpret and respond to virtual symbols. These factors and their definitions are as follows:

Openness. This dimension refers to an individual's level of intellectual curiosity. It also pertains to a person's ability to contend with abstract ideas and a facility for thinking symbolically. We would expect that the higher scores on this dimension would correspond with individuals attaching more realism to the digital symbols contained within a virtual shopping environment which would in turn lead to a more favorable response to the virtual shopping environment.

Conscientiousness. This factor refers to a person's tendency to be oriented toward structure as opposed to being spontaneous to external objects. In comparison to the brick and mortar store, the virtual shopping store contains fewer objects (symbols) that a person has to cognitively process. This would lead to a more structured perceptual environment. We anticipated that higher scores on this dimension would influence a shopper's ability to better define and cognitively concretize the virtual situation, thus affecting a more positive response to online shopping.

Extraversion. This personality dimension pertains to the extent to which a person is sociable and outgoing in social affairs. Within the psychological literature, extraversion has been shown to affect positive emotional experiences towards objects (Larson and Ketelaar, 1991; Costa and McCrae, 1980) [13] [14]. "Positive emotionality consists of extraversion-sociability traits (e.g., social potency, and activity) that appear to promote positive emotional experiences” (Larson and Ketelaar, 1991, p. 132) [14]. We expect that higher scores on extraversion will be related to higher scores on individual's attitudes towards online shopping because of their more aptnesses to attached positive experiences to things such as digital symbols.

Neuroticism. This dimension refers to a person's level of emotional stability. A person scoring high on this scale would exhibit various normal situations as threatening. Larson and Ketelaar again stated: "Negative emotionality is associated with a number of primary neurotic traits, such as stress reaction, alienation, and self-descriptions of worry, anxiety, feeling victimized, and resentfulness. Such a neurotic trait cluster appears to foster negative emotional experiences (p. 132).” We expected that a person scoring high on the neurotic orientation may define the virtual merchandising environment as more threatening than a person scoring lower on this dimension. We thus anticipated a negative correlation between neuroticism and shopper attitudes toward online shopping.

We have described the anticipated direct relationship between each of the personality factors with the attitudes towards online shopping. However, exploring how each of the personality factors may moderate the relationship between presence and shopper attitudes is conceptualized as a more significant approach within the symbolic interaction framework. The personality factors, which are conceptualized as a factor affecting how a situation is being defined, are expected to determine the manner in which a person's sense of presence affects online shopping attitudes.

\section{Research Hypotheses}

This study investigated the following research hypotheses:

H1. There is a positive relationship between a person's perceptions of the level of presence within a virtual merchandising environment and their attitudes toward virtual shopping.

H2. There is a positive relationship between the degree of individual's openness and their attitudes toward virtual shopping.

H3. There is a positive relationship between the degree of individual's conscientiousness and their attitude toward virtual shopping.

H4. There is a positive relationship between the degree of individual's extraversion and their attitudes toward virtual shopping.

H5. There is a negative relationship between the degree of individual's neuroticism and their attitudes toward virtual shopping.

H6. Each of the four personality dimensions will moderate the relationship between individual's perceptions of presence within a virtual shopping environment and their attitudes towards online shopping. 


\section{Methodology}

\subsection{Sample}

This study was conducted among 81 undergraduate students of Apparel, Textiles and Merchandising at a Midwestern university. The sample was a purposive convenience sample, consisting of students ranging from 17 57 years of age. A summary of the demographic profile of the sample is provided in Table 1. Students were asked to view a website of one of the largest general merchandising retailers in America, which has an online store as well as a brick and mortar presence. This website has been ranked as one of the most-visited retail websites. The responders were given exactly twelve minutes to browse the website and an additional eight minutes to complete the survey questions used for this study.

\subsection{Structure of the Online Store}

The mass-merchant website used in this study was structured in a logical, linear format. This is consistent with our belief that such a structured environment would positively affect the dimensions of symbolic interaction theory pertaining to how symbols impact a person's perception of reality. It consisted of a home page as the tier one layer with a classification system used for product, brand selection, and categories. The online consumer interface was interactive, offering the customer the ability to choose from a variety of options. This second tier engaged the customer to make additional decisions in their selection such as size, quantity, color, and furthering their depth of selection by using a zoom function for product details, for example, the front and back 2-dimensional views for visualization of product construction detailing, and color imaging. The site offered an overview of the product, such as fiber content, care instructions, a consumer rated feedback mechanism, along with suggestive marketing of other accessories for purchase. The final tier was the checkout/payment process featuring an additional point of sale merchandising option that would bundle items into the total purchase if selected by the customer. The payment terms and shipping information could be completed in a four-step process, finalizing the sale with a customer satisfaction survey.

\subsection{Measurement}

Each of the scales utilized within the survey questionnaire consisted of a five-point and five-anchor Likert type scale.

\subsubsection{Presence}

A modified version of the Witmer \& Singer (1998) [10] presence scale was utilized to measure presence. The scale consisted of 17 items. The Chronbach reliability score for this scale was 0.75 .

\subsubsection{Shopping Attitudes}

Two different measurements of attitudes toward online shopping were utilized within this survey designed by the authors. The first measurement consisted of three items that focused on the shopper's general attitude toward shopping online. These questions represented the first measurement (Attitudes 1) and comprise of the following three items:

1) In the future, I will be more willing to shop online.

2) I enjoyed the online shopping experience.

3) My online shopping experience is better to me than my experience with traditional shopping.

The Chronbach Alpha reliability score for this scale was 0.82

The second measurement (Attitudes 2) consisted of three items asking the respondents to describe their online experience in comparison to their experience with shopping in a brick and mortar store. The following are the three items:

\section{Table 1. Demographic summary.}

\begin{tabular}{|c|c|c|c|c|c|c|c|c|c|c|c|}
\hline \multicolumn{2}{|c|}{ GENDER } & \multicolumn{5}{|c|}{ ETHNICITY } & \multicolumn{5}{|c|}{ GRADE LEVEL } \\
\hline Male & Female & White & Black & Indian & Asian & Hispanic & Fresh & Soph. & Jun. & Sen. & Grad. \\
\hline 14 & 67 & 31 & 56 & 2 & 5 & 3 & 9 & 15 & 17 & 31 & 9 \\
\hline
\end{tabular}


1) In comparison to shopping in an actual store, when browsing within the virtual store, the objects appeared realistic.

2) In comparison to shopping in an actual store, when browsing within the virtual store, I was more enticed to purchase items.

3) In comparison to shopping in an actual store, when browsing within the virtual store, I felt that it was more convenient to shop.

The Chronbach Alpha reliability score for this scale was 0.71 .

The four personality factors personality factors consisting of openness, conscientiousness, extraversion, and neuroticism were measured with a modified version of a scaled developed by McCrae and Costa (1987) [15]. The scales for each of these factors were recorded into high and low categories according to the range of scores for each dimension. This was done to test for their moderator influence on the relationship between consumer perceived presence and their attitudes toward virtual shopping.

The number of items for each factor and their resulting reliability score is presented within Table 2.

\section{Results}

H1. There is a positive relationship between a person's perceptions of the level of presence within a virtual merchandising environment and their attitudes toward virtual shopping.

As revealed in Table 3, an individual's level of presence has a positive and statistically significant correlation with both measures of online attitudes toward shopping online. Attitude I pertains to the individual's overall satisfaction with online shopping. Attitude II pertains to the consumer's perception of online shopping in comparison to brick and mortar shopping experiences. Hypothesis one is supported.

H2. There is a positive relationship between the degree of individual's openness and their attitudes toward virtual shopping.

As revealed in Table 3, the degree of openness is not significantly related the participants within this study attitudes towards online shopping. This hypothesis is not supported.

Table 2. Reliability scores of big five personality scales.

\begin{tabular}{ccc} 
& Number of items & Chronbach's $\alpha$ \\
\hline Openness & 6 & 0.75 \\
Conscientiousness & 5 & 0.77 \\
Extraversion & 9 & 0.91 \\
Neuroticism & 8 & 0.90 \\
\hline
\end{tabular}

Table 3. Relationships between presence, personality factors and attitudes towards online shopping.

\begin{tabular}{cccc}
\hline $\mathbf{N}=\mathbf{8 1}$ VARIABLES & R2 & Beta & Sig \\
\hline Presence on Attitudes One & 0.308 & 0.438 & 0.000 \\
Presence on Attitudes Two & 0.147 & 0.160 & 0.000 \\
Openness on Attitudes One & 0.043 & 0.105 & 0.700 \\
Openness two on Attitudes Two & 0.012 & 0.110 & 0.330 \\
Conscientiousness on Attitudes One & 0.006 & 0.202 & 0.497 \\
Conscientiousness on Attitudes Two & 0.043 & 0.227 & 0.062 \\
Extraversion on Attitudes One & 0.000 & 0.017 & 0.946 \\
Extraversion on Attitudes Two & 0.001 & 0.012 & 0.771 \\
Neuroticism on Attitudes One & 0.013 & -0.111 & 0.317 \\
Neuroticism on Attitudes Two & 0.005 & 0.028 & 0.541 \\
\hline
\end{tabular}


H3. There is a positive relationship between the degree of individual's conscientiousness and their attitude toward virtual shopping.

This hypothesis is not supported by the results as indicated in Table 3.

H4. There is a positive relationship between the degree of individual's extraversion and their attitudes toward virtual shopping.

The degree extraversion of individuals within this particular study is not shown to be related to their attitudes about online shopping as revealed in table two. This hypothesis is not supported.

H5. There is a negative relationship between the degree of individual's neuroticism and their attitudes toward virtual shopping.

Once again, as shown in Table 2, this hypothesis is not supported.

H6. Each of the four personality dimensions will moderate the relationship between individual's perceptions of presence within a virtual shopping environment and their attitudes towards online shopping.

Table 4 and Table 5 present the regression analysis for the relationship between presence and the two outcome measurements of attitudes toward shopping online as moderated by each of the personality factors. Presence was shown to have a direct influence on individuals' perceptions of online shopping for both outcome factors. However, this relationship is shown to be weaker among each of the categories of the openness and conscientiousness personality factors relevant to the attitude one variable (Table 3). For the attitude two variable, the moderated regression coefficients are also shown to be lower than the direct relationship with the exception of the low openness category. These results indicate that the openness and conscientiousness personality variables are important factors to consider when analyzing the relationship between perceptions of presence and individual's shopping attitudes towards virtual merchandising.

Table 4 reveals that the extraversion and neuroticism personality factors have a different impact on the presence and attitudes towards online shopping relationship. To begin with, the correlation between presence and attitude one is somewhat higher within the low extraversion and low neuroticism categories. On the other hand, no significant relationship is shown within the high neuroticism category. This indicates that the only category within the present study where no significant relationship is found between presence and shopping attitudes is for individuals who scored high on the neuroticism measure.

In regards to the relationship between presence and attitude two, the direct relationship between these two variables is shown to be only moderate although statistically significant. However, when analyzing this relationship within the categories of low extraversion and high neuroticism we discover the highest relationships within the study. Attitude two is a comparison of perceptions between the online and brick and mortar store shopping

Table 4. The relationship between presence and attitudes towards online shopping moderated by openness and conscientiousness.

\begin{tabular}{|c|c|c|c|c|c|c|c|c|c|c|c|c|c|c|c|}
\hline \multicolumn{16}{|c|}{ Moderator Variables } \\
\hline \multirow{2}{*}{$\begin{array}{l}\text { Direct Relationship } \\
\qquad \mathbf{N}=\mathbf{8 1}\end{array}$} & \multirow[b]{2}{*}{ R2 } & \multirow[b]{2}{*}{ Beta } & \multirow[b]{2}{*}{ Sig } & \multicolumn{3}{|c|}{$\begin{array}{c}(n=34) \\
\text { Low Openness }\end{array}$} & \multicolumn{3}{|c|}{$\begin{array}{c}(n=47) \\
\text { High Openness }\end{array}$} & \multicolumn{3}{|c|}{$\begin{array}{c}(n=43) \\
\text { Low Concient. }\end{array}$} & \multicolumn{3}{|c|}{$\begin{array}{l}\quad(\mathrm{n}=48) \\
\text { High Concient. }\end{array}$} \\
\hline & & & & $\mathbf{R 2}$ & Beta & Sig & $\mathbf{R} 2$ & Beta & Sig & $\mathbf{R} 2$ & Beta & Sig & $\mathbf{R} 2$ & Beta & Sig \\
\hline Presence on Attitudes One & 0.308 & 0.438 & 0.000 & 0.213 & 0.459 & 0.008 & 0.186 & 0.410 & 0.006 & 0.109 & 0.387 & 0.00 & 0.231 & 0.447 & 0.002 \\
\hline Presence on Attitudes Two & 0.147 & 0.160 & 0.000 & 0.199 & 0.182 & 0.008 & 0.121 & 0.147 & 0.018 & 0.113 & 0.156 & 0.029 & 0.053 & 0.111 & 0.063 \\
\hline
\end{tabular}

Table 5. The relationship between presence and attitudes towards online shopping moderated by extraversion and neuroticism.

\begin{tabular}{|c|c|c|c|c|c|c|c|c|c|c|c|c|c|c|c|}
\hline \multicolumn{16}{|c|}{ Moderator Variables } \\
\hline \multicolumn{4}{|l|}{ Direct Relationship } & \multicolumn{3}{|c|}{$\begin{array}{c}(\mathrm{n}=34) \\
\text { Low Extraversion }\end{array}$} & \multicolumn{3}{|c|}{$\begin{array}{c}(n=47) \\
\text { High Extraversion }\end{array}$} & \multicolumn{3}{|c|}{$\begin{array}{c}(n=43) \\
\text { Low Neuroticism }\end{array}$} & \multicolumn{3}{|c|}{$\begin{array}{c}\quad(n=48 \\
\text { High Neuroticism }\end{array}$} \\
\hline $\mathbf{N}=\mathbf{8 1}$ & R2 & Beta & Sig & $\mathbf{R} 2$ & Beta & Sig & R2 & Beta & Sig & $\mathbf{R} 2$ & Beta & Sig & R2 & Beta & Sig \\
\hline Presence on Attitudes One & 0.308 & 0.438 & 0.000 & 0.355 & 0.679 & 0.002 & 0.150 & 0.380 & 0.003 & 0.383 & 0.590 & 0.000 & 0.067 & 0.297 & 0.102 \\
\hline Presence on Attitudes Two & 0.147 & 0.160 & 0.000 & 0.422 & 0.289 & 0.001 & 0.079 & 0.116 & 0.036 & 0.190 & 0.132 & 0.006 & 0.340 & 0.173 & 0.030 \\
\hline
\end{tabular}


experiences. This finding seems to indicate that the relationship between presence and this outcome variable is more relevant for individuals who are more oriented towards introversion and neuroticism more so than individuals scoring high on extraversion and low on neuroticism.

\section{Discussion and Conclusions}

This study explored the relationships between personality characteristics and their influence on the relationships between the perceived presence of consumers and their attitudes towards online shopping. The results supported our expectations that there would be a positive correlation between the levels of sense of presence within an online shopping environment and individuals' satisfaction with their online browsing experience. We believe that this finding has important practical implications for retailers who are choosing to promote their products within an online virtual environment. Retailers should be very conscious of how they symbolically structure their website in terms of the realism which the site conveys to the consumer; this in turn enhances their sense of presence within the website and perhaps their willingness to make purchases.

Two of the personality factors were shown to have the strongest influence on the correlation between an individual's sense of presence and their attitudes towards online shopping: Extraversion and Neuroticism. The stronger correlation shown for introverts (low extraversion) than for individuals scoring higher on the extraversion scale could possibly indicate the need for online shopping websites to have more realism in the design of the website in its presentation of products to introverts in comparison to more extraverted individuals. From a symbolic interactionist perspective, this alludes to the idea that introverted individuals may have a need for symbols to be more realistically displayed in order to more succinctly define the virtual situation as real. This finding challenges us to conduct more research on this interesting proposition.

Taken altogether, each of the categories of the personality types explored within the study revealed different relationships between presence and online shopping attitudes compared with the direct relationship. This indicates that the personality factor is very relevant to the design of virtual websites.

This was an observational pilot study using a small convenience sample size of 81 comprised of a population of undergraduate students enrolled in an Apparel, Textiles and Merchandising program of study. An important finding was that the degree of perceived presence of a virtual merchandising platform does influence attitudes towards online shopping. Further studies may explore topics such as the interactive nature of the online environment as perceived by various personality types. Secondly, we suggest that future studies include virtual stores that vary according to the manner in which the products are organized to determine the effect that these differences have on consumer shopping attitudes.

We believe that focusing on research on how digital symbols within online stores affect shoppers' sense of presence, coincides with the recent emphasis on planned behavior (Aggeri, et al., 2005). This framework focuses on the need for the retailing practices of businesses to be more concerned with various aspects of the consumer as opposed to being overly concerned with making a profit.

\section{References}

[1] Mead, G.H. (1934) Mind, Self, and Society. University of Chicago Press, Chicago.

[2] Bellamy, A. and Hanewicz, C. (1999) Social Psychological Dimensions of Electronic Communication. Electronic Journal of Sociology, 4, 1-22.

[3] Venkatesh, V. and Agarwal, R. (2006) Turning Visitors into Customers: A Usability-Centric Perspective on Purchase Behavior in Electronic Channels. Management Science, 52, 367-382. http://dx.doi.org/10.1287/mnsc.1050.0442

[4] Vogelstein, F. (2003) Mighty Amazon Jeff Bezos. FORTUNE Magazine, 147, 60.

[5] Childers, T.L., Carr, C.L., Peck, J. and Carson, S. (2002) Hedonic and Utilitarian Motivations for Online Retail Shopping Behavior. Journal of Retailing, 77, 511-535. http://dx.doi.org/10.1016/S0022-4359(01)00056-2

[6] Kim, Y.K., Kim, E.Y. and Kumar, S. (2003) Testing the Behavioral Intentions Model of Online Shopping for Clothing. Clothing and Textiles Research Journal, 21, 32-40. http://dx.doi.org/10.1177/0887302X0302100104

[7] Lee, H.H., Kim, J. and Fiore, A.M. (2010) Affective and Cognitive Online Shopping Experience Effects of Image Interactivity Technology and Experimenting with Appearance. Clothing and Textiles Research Journal, 28, 140-154. http://dx.doi.org/10.1177/0887302X09341586

[8] Yang, H.E. and Wu, C.C. (2009) Effects of Image Interactivity Technology Adoption on Eshoppers' Behavioural Intentions with Risk as Moderator. Production Planning and Control, 20, 370-382. 
http://dx.doi.org/10.1080/09537280902843755

[9] Barkhi, R. and Wallace, L. (2007) The Impact of Personality Type on Purchasing Decisions in Virtual Stores. Information Technology and Management, 8, 313-330. http://dx.doi.org/10.1007/s10799-007-0021-y

[10] Witmer, B.G. and Singer, M.J. (1998) Measuring Presence in Virtual Environments: A Presence Questionnaire. Presence: Teleoperators and Virtual Environments, 7, 225-240. http://dx.doi.org/10.1162/105474698565686

[11] Lombard, M. and Ditton, T. (1997) At the Heart of It All: The Concept of Presence. Journal of Computer-Mediated Communication, 3, 0-0. http://dx.doi.org/10.1111/j.1083-6101.1997.tb00072.x

[12] Goldberg, L.R. (1993) The Structure of Phenotypic Personality Traits. American Psychologist, 48, 26-34. http://dx.doi.org/10.1037/0003-066X.48.1.26

[13] Costa, P. and McCrae, R. (1980) Influence of Extraversion and Neuroticism on Subjective Well-Being: Happy and Unhappy People. Journal of Personality and Social Psychology, 38, 668-678. http://dx.doi.org/10.1037/0022-3514.38.4.668

[14] Larsen, R. and Ketalaar, T. (1991) Personality and Susceptibility to Positive and Negative Emotional States. Journal of Personality and Social Psychology, 61, 132-140. http://dx.doi.org/10.1037/0022-3514.61.1.132

[15] McCrae, R. and Costa, P. (1987) Validation of the Five-Factor Model of Personality across Instruments and Observers. Journal of Personality and Social Psychology, 52, 81-90. http://dx.doi.org/10.1037/0022-3514.52.1.81 